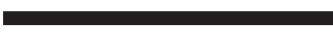

AUTORES:

Tatiana Lima Boletini

Cristina Carvalho de Melo

Camila Cristina F Bicalho

Franco Noce

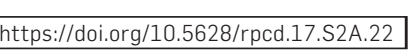

\section{Disciplina e bullying \\ em alunos do ensino \\ fundamental}

PALAVRAS CHAVE:

Aluno. Bullying. Disciplina.

Comportamento agressivo.

\title{
RESUMO
}

0 objetivo do presente estudo foi verificar a relação entre disciplina e o comportamento agressivo "bullying" de alunos do ensino fundamental, de ambos os sexos, de escolas públicas e privadas da cidade de Belo Horizonte. Foram avaliados 235 estudantes entre 10 e 17 anos e 18 professores das mesmas escolas. Os instrumentos utilizados foram o Questionário de Comportamento Agressivo Dirigido aos Alunos e o Questionário Sobre o Conceito de Disciplina Dirigido aos Professores e aos Alunos. 0 tratamento estatístico foi realizado pelo pacote SPSS e Excel através de análise descritiva. Os resultados mostraram que o comportamento agressivo mais comum na visão dos alunos é o verbal e indireto, os lugares onde mais ocorrem são em sala de aula com o professor ausente e no pátio da escola. Alunos com menor escolaridade se identificam mais claramente como vítimas e os de maior escolaridade como agressores. Conclui-se que a relação professor-aluno é o melhor caminho para se alcançar a disciplina, enquanto que a punição é a medida menos eficiente.

Discipline in relation of verification and bullying

\section{ABSTRACT}

The aim of the study was to investigate the relationship between discipline and aggressive behavior "bullying" of elementary school students of both sexes in public and private schools in the city of Belo Horizonte. We evaluated 235 students between 10 and 17 years and 18 teachers from the same schools. The instruments used were the Behavior Questionnaire Aggressive Aimed at Students and the Questionnaire About Discipline Concept Aimed at Teachers and Students. Statistical analysis was performed using SPSS and Excel package through descriptive analysis. The results showed the most common aggressive behavior on the student view is verbal and indirect, the places where they most occur are in the classroom with the absent teacher and in the school yard; additionally, students with less years of schooling identify themselves more clearly as victims and students with more years of education are identified as aggressors. As for the discipline, it is concluded that the teacher-student relationship is the most important strategy and that punishment is not the best way to discipline.

KEY-WORDS:

Student. Bullying. Discipline.

Aggressive behavior. 
A escola é um dos principais ambientes de formação do indivíduo. Nela são desenvolvidas a socialização, a promoção da cidadania, e a formação de atitudes e opiniões que podem contribuir com o desenvolvimento ou prejudicar a formação. Esse ambiente é um local privilegiado para refletir sobre diversas questões que ocorrem na sociedade envolvendo os diversos atores, como pais, alunos e professores (Marriel, Assis, Avanci \& Oliveira, 2006)

Dentre as questões mais pertinentes no desenvolvimento dos jovens na escola e suas repercussões na sociedade estão os comportamentos agressivos e os incidentes disciplinares. 0 comportamento agressivo, de acordo com Seixas (2005), conceitua-se como um fenômeno que abrange toda uma variedade de comportamentos de maus-tratos entre estudantes, podendo estas ações ser de caráter físico, verbal, psicológico e social.

Para Fante e Pedra (2008), o bullying é uma das formas de violência mais desafiadoras para a escola e esta expressão, na visão de Wynne e Joo (2011), é empregada para explicar um fenômeno relacional caracterizado pelo comportamento agressivo, cruel, intencional e repetitivo, ocorrendo de forma repulsiva e intimidadora contra uma mesma pessoa ou grupo, principalmente nos períodos da infância e adolescência. 0 bullying pode ser classificado como: a) físico e direto, como agressões físicas, ocorridas mais frequentemente no ensino fundamental I (Seixas, 2012); b) verbal e direto, incluindo os menosprezos insultos em público, ou ressaltar um defeito físico e/ ou de ações de outro aluno (Martins, 2015; Seixas, 2005); c) psicológico e indireto, com ações encaminhadas de forma a diminuir a autoestima do indivíduo e a aumentar sua sensação de insegurança e temor, como por exemplo, através de boatos (Avilés, 2002); d) social e indireto, como o isolamento de um indivíduo e/ ou não permitir que o mesmo participe de um respectivo grupo por ser alvo de rumores desagradáveis ou simplesmente pelo fato de alguns alunos não falarem com este aluno (Seixas, 2005) e, por fim, e) virtual, em que se insulta, discrimina, difama, humilha, e/ ou ofende por meio da internet e/ou aparelho celular (Silva, Dascanio, \& do Valle, 2016).

O levantamento realizado pela Associação Brasileira Multiprofissional de Proteção à Infância e Adolescência (ABRAPIA), em 2002, envolvendo 5875 estudantes de 5aa a $8^{\text {a }}$ séries, de 11 escolas localizadas no município do Rio de Janeiro, revelou que $40.5 \%$ desses alunos admitiram ter estado diretamente envolvidos em atos de bullying, naquele ano, sendo $16.9 \%$ vítimas, $10.9 \%$ vítimas agressivas e $12.7 \%$ agressores. 0 bullying ocorre, principalmente, entre crianças de 10 a 15 anos; porém, não está restrito nem a essa faixa etária nem ao ambiente escolar. No ambiente escolar, foi detectado ainda nessa pesquisa que os meninos estão envolvidos com o bullying de forma muito mais frequente, tanto como agressores quanto como vítimas. Entre as meninas, embora com menor frequência, o bullying também ocorre e se caracteriza, principalmente, como prática da difamação e exclusão. conjunto de regras e obrigações, pode vir acompanhada de sanções, e é construída a partir de uma base de confiança mútua. Segundo Antunes (2002), "a disciplina é o conjunto de mecanismos e estratégias que permitem criar um clima educacional em sala de aula, embora alguns professores prefiram considerá-la como a estratégia da calma, da tranquilidade e do controle para poder ensinar". Na escola, a disciplina é um elemento essencial para o desenvolvimento de qualquer atividade, seja ela individual ou em grupo (Boarini, 2013).

A falta de respeito dos alunos com os professores e a defasagem disciplinar em sala de aula têm contribuído para a omissão de casos de bullying (Barros, Botelho, Santana, \& Oliveira, 2015). Esta omissão não se dá, frequentemente, por negligência, mas por ausência de preparo profissional e falta de informação sobre como atuar na resolução do problema (Bandeira \& Hutz, 2012).

Dessa maneira, observa-se uma relação entre disciplina e o comportamento agressivo (Lopes Neto, 2005), neste caso o bullying. Os relacionamentos interpessoais positivos estabelecem uma relação direta com o desenvolvimento acadêmico, sendo a aceitação pelos companheiros fundamental para o desenvolvimento da saúde de crianças e adolescentes, aprimorando suas habilidades sociais e fortalecendo a sua capacidade de reação diante de situações de tensão (Lopes Neto, 2005).

Atualmente, comportamentos agressivos dentro da escola por parte de alunos são um dos maiores motivos de preocupação para professores, pais, a comunidade e, principalmente, para os próprios alunos (Martins, 2015). Segundo Oliveira, Costa e Oliveira (2014), situações de violência na escola são bastante frequentes, sendo que este tipo de comportamento pode causar sérias consequências e efeitos negativos para o desenvolvimento e para a saúde mental dos jovens envolvidos. Devido a este número crescente de agressões verbais, físicas, sociais e psicológicas entre alunos, dentro e fora da escola, e a pouca exploração na literatura existente da relação entre disciplina e comportamento agressivo (bullying) na escola, o objetivo deste estudo foi verificar a ocorrência de comportamento agressivo - bullying - e o conceito de disciplina por parte dos alunos e professores de 5 o a 8 anos do ensino fundamental de escolas públicas e particulares.

\section{MÉTODO}

AMOSTRA

Utilizando uma amostra de conveniência, participaram do estudo 235 alunos (115 do sexo masculino) com idades entre 11 e 17 anos, do $5^{\circ}$ ao $8^{\circ}$ ano do ensino fundamental de duas escolas da cidade de Belo Horizonte, uma pública e outra privada. Também fizeram parte da amostra 18 professores das escolas pesquisadas. 
INSTRUMENTOS

Foram utilizados dois instrumentos para avaliar o comportamento agressivo e a disciplina ambos compostos por uma ficha de dados pessoais para caracterização da amostra.

Para caracterização do comportamento agressivo foi aplicado o instrumento adaptado de Ortega, Mora-Merchán e Mora (1995) por Avilés (2002), composto por 12 questões de múltipla escolha que avaliaram os tipos de bullying, os lugares e a freqüência de ocorrência. Este instrumento distingue as vítimas, os agressores, as vítimas agressivas e os alunos com nenhum envolvimento, além do motivo que levam os alunos a se tornarem agressores, quem costuma parar os comportamentos agressivos e as possíveis soluções para que se diminuam estes comportamentos na escola.

O instrumento sobre disciplina utilizado foi o questionário Q Des - Adaptado, de Brito (1993), "versão conceito de disciplina". Este instrumento verificou o conceito de disciplina por parte dos alunos de educação física de escolas públicas e particulares e professores das mesmas instituições. 0 Questionário Q Des - Adaptado consta de 25 diferentes medidas, as quais o professor e os alunos avaliam numa escala de afirmativas de cinco valores, sendo: (-2) Discordo Totalmente (DT); (-1) Discordo (D); (0) Não tenho opinião (NTO); (+1) Concordo (C);(+2) Concordo Totalmente (CT).

PROCEDIMENTOS

Para a realização da pesquisa, foi solicitada uma autorização à direção das escolas. Os dados foram coletados nas escolas no horário de aula, em salas de aula onde somente permaneceram os alunos que participaram da pesquisa.

Em todas as coletas o instrumento foi explicado pelo pesquisador, que forneceu auxílio aos professores e aos alunos em caso de dúvida.

ANÁLISE ESTATÍSTICA

Para verificar o perfil da amostra e analisar os dados do "comportamento agressivo" e da "disciplina" foi utilizada estatística descritiva, de acordo com a natureza de cada variável (paramétrica ou não paramétrica).

CUIDADOSÉTICOS

Este estudo, de caráter voluntário e anônimo, foi aprovado pelo Comitê de Ética do Centro Universitário de Belo Horizonte - Uni-BH protocolo no 055/05, tendo respeitado todas as normas estabelecidas pelo Conselho Nacional em Saúde (196/96) envolvendo pesquisas com seres humanos.

\section{RESULTADOS}

PERFIL DA AMOSTRA

Verifica-se que, do total da amostra dos alunos $(N=235)$, observa-se uma participação homogênea quanto ao caráter escolar público (51\%) e ao caráter escolar particular (49\%). Observa-se ainda que houve um equilíbrio na distribuição da amostra do estudo quanto ao sexo dos participantes, tanto na escola pública quanto privada (QUADRO I).

QUADRO 1. Distribuição da amostra em relação ao caráter escolar e ao gênero.

\begin{tabular}{|c|c|c|c|c|c|c|c|c|c|}
\hline & \multirow{2}{*}{\multicolumn{3}{|c|}{$\begin{array}{c}\text { AMOSTRA } \\
\text { NÚMERO DE ALUNOS }\end{array}$}} & \multicolumn{6}{|c|}{ GÉNERO } \\
\hline & & & & \multicolumn{3}{|c|}{ MASCULINO } & \multicolumn{3}{|c|}{ FEMININO } \\
\hline & 胥 & $\begin{array}{l}\frac{\pi}{0} \\
\frac{0}{30} \\
\frac{0}{2}\end{array}$ & 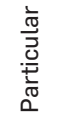 & 丞 & 总 & 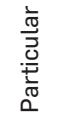 & 点 & $\frac{.00}{-\frac{0}{0}}$ & 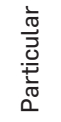 \\
\hline N & 235 & 119 & 116 & 115 & 53 & 62 & 120 & 66 & 54 \\
\hline$\%$ & $100 \%$ & $51 \%$ & $49 \%$ & $49 \%$ & $46 \%$ & $54 \%$ & $51 \%$ & $55 \%$ & $45 \%$ \\
\hline
\end{tabular}

Em relação à série escolar e ao caráter da instituição de ensino, pode-se observar também uma homogeneidade na distribuição da amostra (QUADRO II).

QUADRO 2. Distribuição da amostra em relação ao caráter e a série escolar

\begin{tabular}{|c|c|c|c|c|c|c|c|c|c|c|c|c|}
\hline & \multicolumn{12}{|c|}{ ESCOLARIDADE } \\
\hline & & $5^{\mathrm{a}}$ & & & $6^{\mathrm{a}}$ & & & $7 \mathrm{a}$ & & & $8^{\mathrm{a}}$ & \\
\hline & $\begin{array}{l}\vec{\pi} \\
\vec{\circ}\end{array}$ & $\begin{array}{l}\frac{\pi}{0} \\
\frac{0}{\overline{3}} \\
0\end{array}$ & 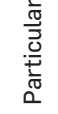 & 氶 & $\begin{array}{l}\frac{\pi}{0} \\
\frac{\overline{0}}{3} \\
0\end{array}$ & 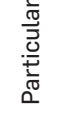 & $\begin{array}{l}\overrightarrow{\widetilde{\sigma}} \\
\stackrel{\circ}{\circ}\end{array}$ & $\begin{array}{l}\frac{\pi}{0} \\
\frac{0}{\overline{3}} \\
\frac{3}{2}\end{array}$ & 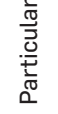 & $\begin{array}{l}\text { 褐 } \\
\end{array}$ & $\begin{array}{l}.00 \\
. \overline{\bar{O}} \\
0\end{array}$ & 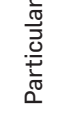 \\
\hline N & 61 & 30 & 31 & 58 & 30 & 28 & 59 & 29 & 30 & 57 & 30 & 27 \\
\hline$\%$ & $26 \%$ & $13 \%$ & $13 \%$ & $25 \%$ & $13 \%$ & $12 \%$ & $25 \%$ & $12 \%$ & $13 \%$ & $24 \%$ & $13 \%$ & $11 \%$ \\
\hline
\end{tabular}

No grupo dos professores investigados $(N=18)$, apresenta-se uma predominância dos que trabalham em escolas públicas $(n=10)$, sendo que mais da metade $(n=10)$ são do gênero feminino.

A questão mais assinalada pela maior parte das turmas se refere ao tipo de bullying classificado como verbal e direto. Já o tipo de bullying denominado como social e indireto foi detectado em maior porcentagem na turma do $8^{a}$ ano particular (FIGURA 1). 


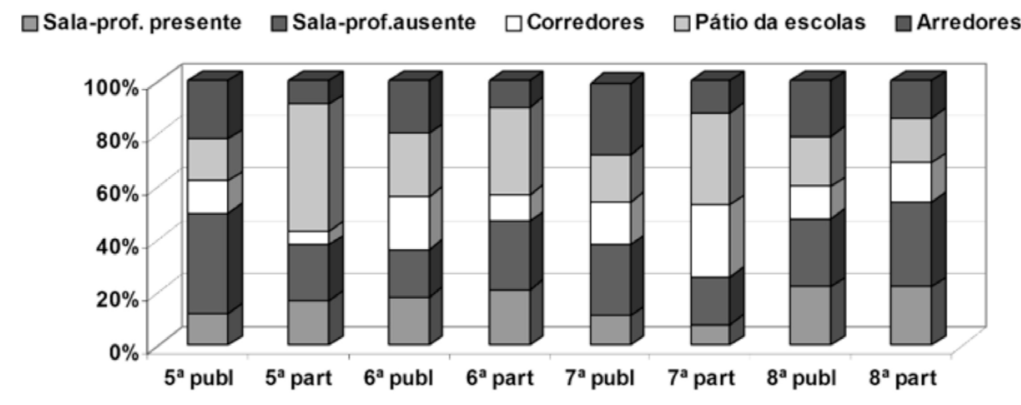

FIGURA 1. Ocorrências mais frequentes dos tipos de bullying nas escolas

Em todas as turmas pesquisadas, a maior parte dos alunos relata que poucas vezes têm ocorrido casos de comportamento agressivo (bullying) na escola. Uma porcentagem menor relata que estes comportamentos ocorrem muitas vezes e quase todos os dias (FIGURA 2).

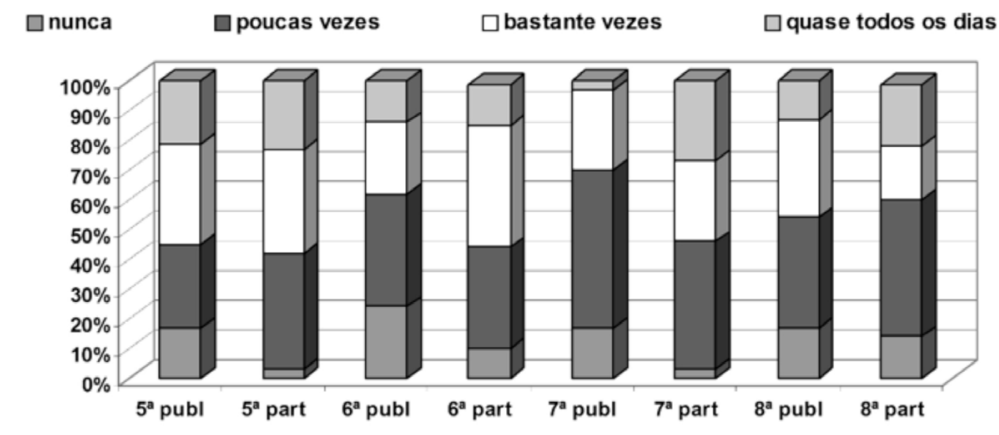

FIGURA 2. Frequência de bullying na escola durante o ano.

Pode-se observar na figura 3 que a maioria dos alunos relataram nunca terem sido vítimas de comportamento agressivo (bullying).

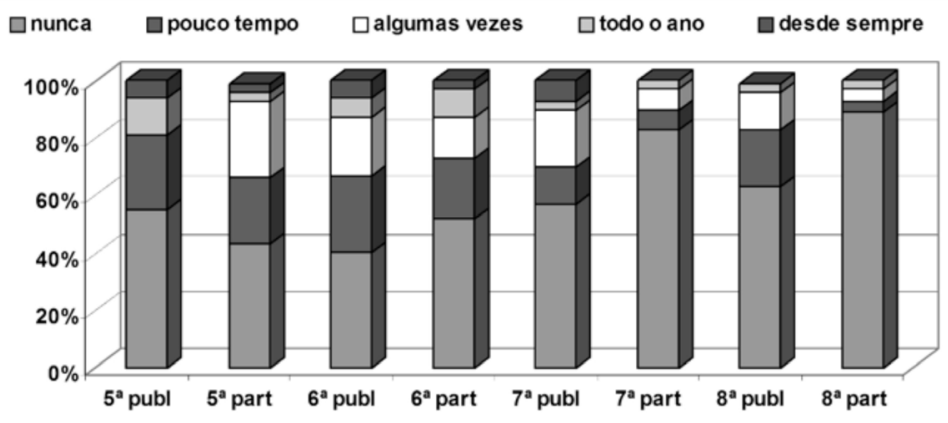

FIGURA 3. Frequência em que os alunos se encontram como vítimas de bullying.
Grande parte dos alunos relata que os lugares em que ocorrem com maior frequência comportamentos agressivos (bullying) são em sala de aula, com o professor ausente, e no pátio da escola (FIGURA 4).

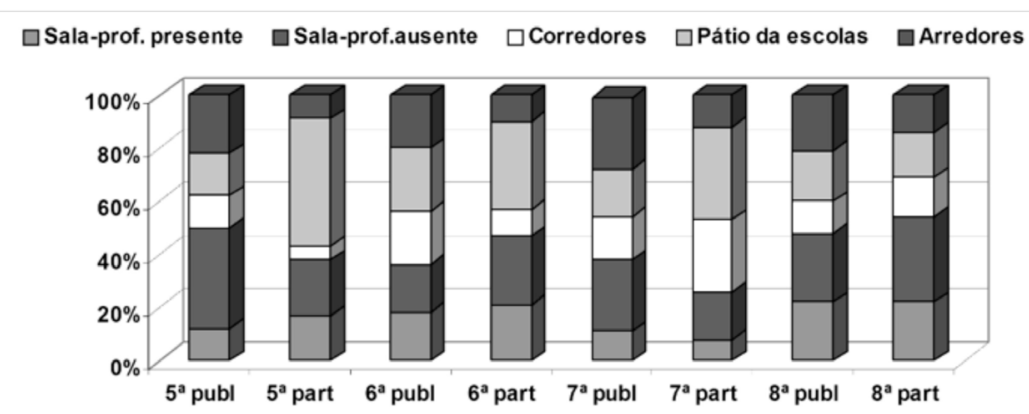

FIGURA 4. Lugares em que ocorrem com maior frequência os comportamentos agressivos (bullying)

Verifica-se na figura 5 que, na visão da maior parte das turmas, quem costuma parar os comportamentos agressivos são os professores e os colegas. Destaca-se ainda um percentual significativo de alunos que relatam que ninguém para estes comportamentos agressivos na escola.

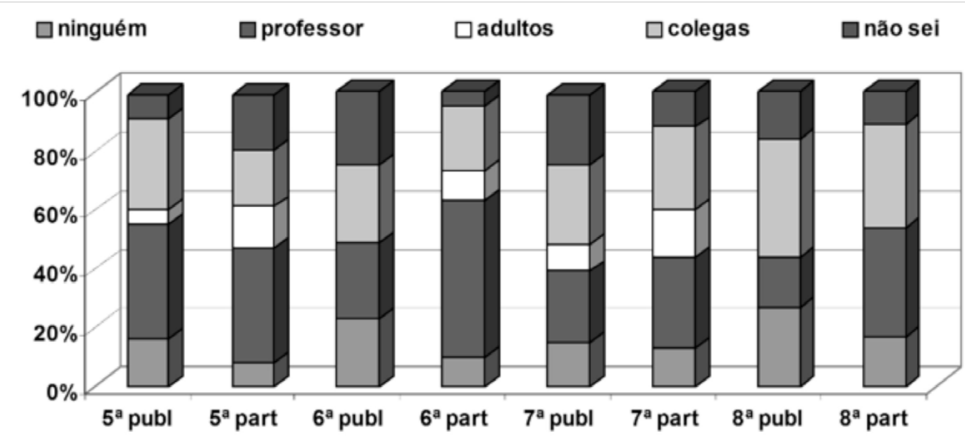

FIGURA 5. Quem costuma parar os comportamentos agressivos.

A figura 6 demonstra que, na opinião dos alunos, os comportamentos agressivos diminuiriam se os professores fizessem algo. Um percentual menor, mas ainda significativo, relata que as agressões diminuiriam com intervenções familiares e dos colegas. 


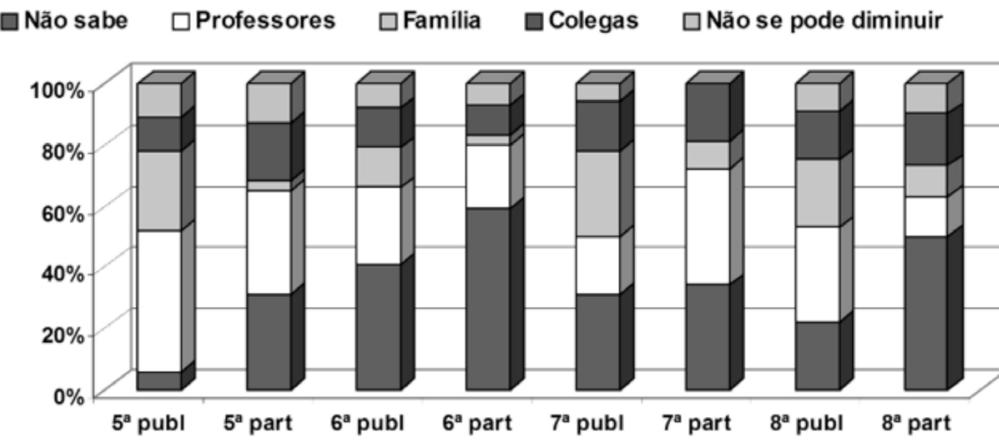

FIGURA 6. Soluções, na visão dos alunos, para diminuição dos comportamentos agressivos.

Na visão dos alunos, os conceitos de disciplina mais acentuados, tanto da escola particular como pública, foram: (\#10) "a principal função da disciplina nas aulas é atuar na formação moral do aluno" e (\#24) "disciplina é básica para se obter bons resultados". Observa-se também que o conceito (\#17) "quanto mais distante for a relação entre professor e aluno, melhor para a disciplina do grupo" foi o que as turmas mais discordaram, tanto pública quanto a particular.

Ao se comparar os conceitos de disciplina na visão dos professores (FIGURA 8), detectou-se divergências de opiniões em conceitos como (\#13) "a forma de disciplina a ser adotada deve ser flexível em relação ao cumprimento das normas". Na visão dos professores de escolas particulares há certa concordância, mas os professores de escolas públicas discordam da mesma. Destaca-se também que os professores de escolas particulares discordam do conceito (\#19) "punições são válidas para disciplinar os alunos".

\section{DISCUSSÃo}

No estudo atual, a questão mais assinalada pela maior parte das turmas se refere ao tipo de bullying classificado como verbal e direto, resultado confirmado por outro estudos realizado por Silva et al. (2016), no qual adolescentes classificaram o tipo de bullying mais prevalente o verbal.

Em relação a ocorrência de bullying nas escolas, a maior parte dos alunos relata que poucas vezes têm ocorrido casos de comportamento agressivo na escola, como demonstrado na figura 2, sendo que em estudos realizados por Melim e Pereira (2013) verificou-se que a frequência do bullying é mais elevada entre os alunos mais novos e que estes enfrentam um bullying mais direto e físico do que os seus colegas mais velhos.
A figura 3 revela que a maioria dos alunos relatam nunca terem sido vítimas de comportamento agressivo. Em contrapartida, da Silva e Fauston (2013) realizaram um estudo com estudantes universitários e a maior parte relatou ter sido vítima de comportamento agressivo e sofrido com alguma forma de violência durante a escolarização na infância e adolescência.

Grande parte dos alunos relata que os lugares em que ocorrem com maior frequência comportamentos agressivos são em sala de aula, com o professor ausente, e no pátio da escola (FIGURA 4). Santos e Kienen (2014) também verificaram que as ocorrências de bullying em sala de aula são onde o fenômeno mais ocorre. Já da Silva e Fauston (2013) destacam o recreio como o local onde ocorrem grande parte dos comportamentos agressivos.

Os resultados do presente estudo demonstraram que, na visão da maior parte das turmas, quem costuma parar os comportamentos agressivos são os professores e os colegas. Os mesmos resultados foram encontrados por Santos e Kienen (2014) e Santos, Perkoski e Kienen (2015), os quais identificaram que as ações destacadas por professores e alunos se focavam em remediar ou punir ocorrências de bullying.

Na visão dos alunos, os comportamentos agressivos diminuiriam se os professores fizessem algo. Teixeira, Salinet, Estabile, Mezzaroba e Soares (2015) e Weimer e Moreira 2014) relataram, em seus estudos, que alunos tendem a contar com a ajuda dos professores com o objetivo de amenizar os comportamentos agressivos.

Ao se compararem os conceitos de disciplina na visão dos professores detectaram-se divergências de opiniões em conceitos como "a forma de disciplina a ser adotada deve ser flexível em relação ao cumprimento das normas". Na visão dos professores de escolas particulares há certa concordância, mas os professores de escolas públicas discordam da mesma. Tiba (2006) e Lima (2012) definem disciplina como a qualidade que faz o ser humano cumprir suas propostas, mesmo sem ser cobrado por alguém, pois sabe que a responsabilidade é sua; ou seja, o professor deve motivar o aluno e nunca medir forças com eles.

Destaca-se também que os professores de escolas particulares discordam do conceito "punições são válidas para disciplinar os alunos". Castro e Santos (2015) verificaram que as atitudes dos professores podem contribuir para melhoria no contexto de ensino-aprendizagem. Diante disso, o professor necessita refletir e propor soluções conjuntas com os alunos para se obter bons resultados. Esses achados corroboram com o presente estudo, no qual os conceitos de disciplina mais acentuados na visão dos alunos, em concordância tanto da escola particular como pública, foram (\#10) "a principal função da disciplina nas aulas é atuar na formação moral do aluno" e conceito (\#24) "disciplina é básica para se obter bons resultados".

A discordância mais acentuada, tanto para os alunos da escola pública quanto a particular, sobre o conceito de disciplina foi (\#17) "quanto mais distante for a relação entre professor e aluno, melhor para a disciplina do grupo". Este aspecto é confirmado por Tiba (2006), que diz que "...um dos grandes geradores de indisciplina está em um professor impor seu poder sobre os alunos, e estes não lhe reconhecerem a autoridade". 
Conclui-se que a disciplina deve ser construída e trabalhada através do respeito mútuo entre os próprios alunos e entre alunos e professores, podendo assim diminuir os comportamentos agressivos entre alunos nas escolas. 0 tipo de comportamento agressivo - bullying - mais praticados nas escolas, na visão dos alunos da escola pública e particular, é o verbal e indireto. Pode-se observar também que a literatura existente sobre a temática reforça que alunos com anos de escolaridade mais baixos se identificam mais claramente como vítimas e alunos com anos de escolaridade mais elevados se identificam como agressores. As vítimas relataram que são agredidos porque são fracos e os agressores justificam as agressões realizadas como uma resposta às agressões sofridas, o que os classificam como vítimas agressivas.

Observou-se que os lugares onde mais ocorrem comportamentos agressivos são em sala de aula, com o professor ausente, e no pátio da escola, e que estes alunos vítimas recorrem aos colegas e professores para que os ajudem a cessar as agressões sofridas. $\mathrm{Na}$ opinião dos mesmos, os comportamentos agressivos diminuiriam se houvesse intervenções dos professores, dos familiares e dos colegas.

Em relação ao conceito de disciplina aceito pelos alunos observou-se que o conceito "quanto mais distante for a relação entre professor aluno, melhor para a disciplina dos alunos" e o conceito "punições são válidas para disciplina os alunos" foram aquelas com que os alunos mais discordaram. Isto atribui ao professor mais uma responsabilidade, a de compreender seus alunos, respeitando suas diferenças e favorecendo a criação de um ambiente escolar realmente propício para o amadurecimento saudável.

Este trabalho buscou investigar e ampliar conhecimentos, bem como reforçar a importância do papel amplo do professor na formação do aluno. Como proposta para estudos futuros, sugere-se verificar o impacto da frequência dos episódios de bullying nas crianças e adolescentes (a médio e longo prazo) e analisar a frequência e características destes episódios após a realização de um programa de intervenção disciplinar. Além disso, espera-se que este trabalho possa contribuir para a reflexão por parte da escola, direção e professores, a respeito da importância de ações de intervenção neste processo.
Avilés, J. M. (2002). Bullying: Intimidación y maltrato entre el alumnado. Bilbao: Stee-Eilas.

Bandeira, C. M., \& Hutz, C. S. (2012). Bullying: Prevalência, implicações e diferenças entre os gêneros. $R$ evista Semestral da Associação Brasileira de Psicologia scolar e Educacional,16(1), 35-44.

Barros, G. C. D. S., Botelho, E. D. S. L., Santana, R. D. F., \& Oliveira, S. D. D. S. (2015). Fatores que influenciam na disciplina escolar: Séries iniciais do ensino fundamental rede pública do distrito federal. Repositorio Instituicional UniCEUB.

Boarini, M. L. (2013) Indisciplina escolar: Uma construção coletiva. Revista da Associação Brasileira de Psicologia Escolar e Educacional, 17(), 123-131. Brito, L. T. M. (1993). O significado da disciplina no trenamento esportivo: Conceitos de treinadores de basquetebol masculino em BH. Dissertação de mestrado, Universidade Federal de Minas Gerais, Brasil.

Castro, J. D. Q., \& Santos, S. F. D. (2015). As causas da indisciplina nas aulas de língua portuguesa: Ação e reflexão da perspectiva docente. In Anais do Congresso de Ensino, Pesquisa e Extensão da UEG (Vol. 2). Fante, C., \& Pedra, J. A. (2008). Bullying escolar: Perguntas \& respostas. Porto Alegre: Artmed.

Lima, V. F. D. (2012). Educação ambiental: aspectos que dificultam o engajamento docente em escolas públicas do Distrito Federal. Dissertacão de mestrado, Universidade de Brasilia, Brasil.

opes Neto, A. A. (2005). Bullying: Comportamento agres sivo entre estudantes. Jornal de Pediatria, 81 (5), 164-172. Marriel, L. C., Assis, S. G., Avanci, J. Q., \& Oliveira, R. (2006). Violência escolar e auto-estima de adolescentes. Cadernos de Pesquisa, 36(127), 35-50.

Martins, E. C. (2015). Incumpridores versus indisciplinados no $1^{10}$ ciclo do ensino básico: Estudo de caso de dois alunos duma escola urbana portuguesa. Interfaces da Educação, 5(15), 165-87.

Melim, M., \& Pereira, B. O. (2013). Bullying, género idade. O Desenvolvimento Humano: Prespetivas para Século XXI, 1, 292-316.

Noce, F., Foreaux, G., Melo, C. C., Costa, G. M. L., \& Costa, V. T. (2011). Análise da eficácia das medidas disciplinadoras em grupos de dança de alto rendimento. Revista Mineira de Educação Física, 19, 84-100.

Oliveira, M. C. M., Costa, J. R. S., \& Oliveira, M. M. (2014). Bullying: Análise do comportamento e mudanças de hábitos nas relações entre crianças em um comunidade escolar. Extensão em Foco, 10, 18-36.
Santos, M. M., \& Kienen N. (2014). Características do bullying na percepção de alunos e profess escola de ensino fundamentat. Temas em Psicolo 22(1), 161-78

Santos, M. M., Perkoski, I. R., \& Kienen, N. (2015) Bullying: Atitudes, consequências e medidas preventivas na percepção de professores e alunos do ensino fundamental. Temas em Psicologia, 23(4), 1017-33. Seixas, S. R. (2012). Violência escolar: Metodologias de identificacão dos alunos agressores e/ ou vítimas. Análise Psicológica, 23(2), 97-110.

da Silva, E. H. B. \& Fauston, N. (2013). Marcas da escola: Relatos de estudantes de pedagogia vítimas do bullying. Trama Interdisciplinar, 4(2), 163-181.

Silva, F., Dascanio, D., \& do Valle, T. G. M. (2016). 0 fenômeno bullying: Diferenças entre meninos e meninas. Reflexão e Ação, 24(1), 26-46.

Teixeira, B. R., Salinet, J. M. Estabile, L. C. Mezzaroba, S. M. B. \& So res, P. G. (2015). Tdentificaca a de situacões de bullying em uma escola de Londina PR. Revista de Ensino, Educaça e Ciencias Humatos, 1 $245-49$

Tiba, I. (2006). Ensinar aprendendo: Novos paradigmas na educação. São Paulo: Integrare.

Weimer, W. R., \& Moreira, E.C. (2014) Violence and bullying: expressions and consequences of Physical Education classes. Revista Brasileira de Ciências do Esporte, 36(1), 257-274.

Wynne, S. L. \& Joo, H. (2011). Predictors of school victimization: Individual, familial, and school factors. Crime \& Delinquency, 57(3), 458-88. 